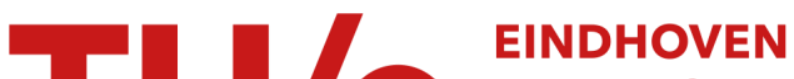 \\ UNIVERSITY OF \\ TECHNOLOGY
}

\section{A decision support and expert system for retail planning}

Citation for published version (APA):

Borgers, A. W. J., \& Timmermans, H. J. P. (1991). A decision support and expert system for retail planning. Computers, Environment and Urban Systems, 15(3), 179-188. https://doi.org/10.1016/0198-9715(91)90007-Z

DOI:

10.1016/0198-9715(91)90007-Z

Document status and date:

Published: 01/01/1991

\section{Document Version:}

Publisher's PDF, also known as Version of Record (includes final page, issue and volume numbers)

\section{Please check the document version of this publication:}

- A submitted manuscript is the version of the article upon submission and before peer-review. There can be important differences between the submitted version and the official published version of record. People interested in the research are advised to contact the author for the final version of the publication, or visit the $\mathrm{DOI}$ to the publisher's website.

- The final author version and the galley proof are versions of the publication after peer review.

- The final published version features the final layout of the paper including the volume, issue and page numbers.

Link to publication

\section{General rights}

Copyright and moral rights for the publications made accessible in the public portal are retained by the authors and/or other copyright owners and it is a condition of accessing publications that users recognise and abide by the legal requirements associated with these rights.

- Users may download and print one copy of any publication from the public portal for the purpose of private study or research.

- You may not further distribute the material or use it for any profit-making activity or commercial gain

- You may freely distribute the URL identifying the publication in the public portal.

If the publication is distributed under the terms of Article 25fa of the Dutch Copyright Act, indicated by the "Taverne" license above, please follow below link for the End User Agreement:

www.tue.nl/taverne

Take down policy

If you believe that this document breaches copyright please contact us at:

openaccess@tue.nl

providing details and we will investigate your claim. 


\title{
A DECISION SUPPORT AND EXPERT SYSTEM FOR RETAIL PLANNING
}

\author{
Aloys Borgers and Harry Timmermans \\ Urban Planning Group \\ Department of Architecture and Urban Planning, \\ Eindhoven University of Technology
}

\begin{abstract}
An important issue in Dutch retail planning practice is prediction of the likely impacts of new retail developments on consumer demand and assessment of the feasibility of new projects. In practice, a planning team has to decide which retail plan out of a number of alternative plans has to be implemented. A decision support system for retail planning can facilitate this decision. The decision support system we are proposing consists of three modules. The first module is used to manage the required data. The second module is used to model consumer choice behaviour. This module also contains the program GIANT, which can be considered as an expert system to assist the analyst in constructing and analysing conjoint-based simulator systems. The third module summarizes and evaluates the predicted impacts of the alternative retail plans.
\end{abstract}

\section{AIMS AND NATURE OF RETAIL PLANNING IN THE NETHERLANDS}

Physical planning has traditionally played an important role in Dutch society. The lack of space, rapid urbanization and the open nature of its society have increased the need to control land development very carefully. Over the years a detailed set of plans and regulations has been approved which regulates future land use. Such plans require the approval of democratically elected councils while the public can also participate in the planning process at various stages. Consequently, there has been a strong tendency during the last 20 years to inform planning proposals with the results of scientific analyses. For example, Dutch law states that a general survey should be conducted before municipalities can start the preparation of their plans.

In practice, the importance of scientific research in the planning process differs considerably between planning sectors. Retail planning is one sector of urban and regional planning with a traditionally strong input of research in the planning and design process. Until a few years ago, municipalities were obliged by law to conduct some kind of retail planning research whenever a new plan was developed. Although this situation has changed somewhat, and this law no longer exists due to the economic crisis and consequent deregulation, every-day practice still

Requests for reprints should be sent to Aloys Borgers, Department of Architecture and Urban Planning, Eindhoven University of Technology, P.O. Box 513, 5600 MB Eindhoven, The Netherlands. 
engages in a considerable amount of applied research, especially when the envisaged changes in the retail structure are substantial.

Perhaps the most important issue in this respect is to predict the likely impacts of new retail developments on consumer demand and assess the feasibility of new projects. The results of such studies are also used to decide on the amount of space and location required by new retail facilities. Traditionally, such decisions were made on the basis of a set of normative ratios between the amount of retail space and the number of inhabitants of the plan area, adjusted according to the type of residential zone involved. It soon became evident, however, that such simple procedures were inadequate to justify the retail plans. Especially the larger scale developments and the peripheral shopping centres had impacts that were beyond previous experience. Starting in the late 1970 s, these developments stimulated the use of more complex research strategies to assess the viability of new retail developments on the one hand and the likely impacts of these new developments on existing shopping centres on the other hand. It resulted in an official government report and a series of guidelines for the Dutch provinces and municipalities, which suggested in a very detailed manner the kind of research these planning agencies had to conduct to substantiate their decision making.

The research effort typically involves a large-scale in-home interview to determine consumer orientation patterns for different types of goods, an inventory of available floor space in the various shopping centres, disaggregated according to type of firm, and an interview with the entrepreneurs. Recently, information about the supply side of the retailing system has been stored in a national geographical information system, which covers most of the country and is developed specifically for retail planning purposes. The consumer interview is used to construct mathematical models of consumer shopping behaviour which predict the likely impacts of policy decisions related to building programs, transportation and retail developments, on the level of retail turnover in the various shopping centres of the study area. The assessment of these effects is typically accomplished by comparing the predicted retail turnover per square foot of floor space with a normative planning standard, derived from a national survey, sometimes adjusted to local circumstances. If changes in retail structure are predicted not to have substantial negative impacts on the level of turnover per square foot floor space, that is, the predicted level of turnover is not lower than the norm, it is generally concluded that the proposed changes in retail structure are justified.

\section{MODELLING CONSUMER CHOICE BEHAVIOUR}

To predict the likely effects of policy measures on the retail system, the effects of those measures on consumer choice behaviour need to be predicted. For this purpose, it is common practice to construct a mathematical model of consumer choice behaviour. In such a model, consumer choice behaviour is explicitly related to a number of features or attributes of the shopping centres, including the distance between residential and shopping centre location. After deciding which type of consumer model will be used and which attributes are to be incorporated in the consumer model (model specification), the exact relationships between choice behaviour and attributes have to be determined (model calibration). Model calibration finally results in a number of parameters which can be considered as weights for the selected attributes. Next, the performance of the model has to be investigated. Only if there is a good fit between observed and predicted choice behaviour, can the model be used to predict consumer choice behaviour at future moments in time, conditional upon the assumption that consumer choice behaviour is stable over time. To predict the likely effects of policy measures on consumer behaviour, the policy measures have to be translated in terms of the attributes of the shopping centres used in the model. Using the adjusted attribute scores, consumer choice behaviour under new circumstances can be predicted. 
In the context of Dutch retail planning, the models used are generally based on observed consumer choice behaviour. In several regions, the conventional spatial interaction model has been used. Further, the multinomial logit model has found ample application. Recently, individually based choice simulator systems based on conjoint measurements have been developed. In contrast to spatial interaction and random utility models which are derived from observed behaviour, the simulator system is based on individuals' expressed or intended behaviour given a number of hypothetical choice alternatives.

\subsection{Models Based on Observed Choice Behaviour}

Spatial interaction models (Wilson, 1971) are based on observed flows of consumers between residential zones and shopping centres. In practice, the origin-constrained version of this model is used to predict the distribution of consumers over the alternative shopping centres, given their residential zone (see, e.g., Roy \& Anderson, 1988). According to this model, the number of consumers visiting a particular shopping centre depends on the (relative) attractiveness of the shopping centre and the (relative) distance between the residential zone and shopping centre. The attractiveness of shopping centres is generally represented by some surrogate variable such as the amount of floor space or number of outlets per shopping centre. Sometimes, the model is generalized to incorporate more explanatory variables in the attractiveness component.

In contrast to spatial interaction models which are based on aggregate flows of consumers, random utility models (e.g., Ben-Akiva \& Lerman, 1985) are based on the observed choice behaviour of individual consumers. The well-known multinomial logit model (McFadden, 1974) is the most frequently used model which can be derived from random utility theory. According to this model, the probability that a consumer chooses a particular shopping centre depends on the relative utility of that centre. The utilities of the shopping centres are assumed to be individual-specific and depend on characteristics of the shopping centres as perceived by each individual. Further, random utility models take into account individual choice sets: only those shopping centres a consumer is familiar with can be chosen by that consumer.

From a theoretical point of view, a random utility model is preferable to a spatial interaction model. In practice, however, predicting the likely effects of policy measures using a random utility model requires the specification of two additional submodels. First, a submodel to construct individual choice sets is required. To determine the set of available shopping centres for each individual consumer, logistic regression analysis may be used (see, e.g., van der Heijden \& Timmermans, 1984). The second submodel is necessary to relate attribute scores as perceived by the individual to objective characteristics of the shopping centres. Curve fitting procedures may be used to determine such relationships.

\subsection{Models Based on Expressed or Intended Choice Behaviour}

In a transportation planning context, this approach has become known as the stated preference approach. The approach has gained increasing popularity in retailing, marketing, recreation, transportation, housing, migration, and other activity based studies (see, e.g., Golledge \& Timmermans, 1988). The model system involves generating hypothetical shopping centres by combining shopping centre characteristics, some of which may be beyond the domain of experience, and then requesting consumers to express some measure of preference for the resulting set of shopping opportunities. Individual preference structures may then be derived from these data and choices may be simulated by implementing some decision rule, for example, that a consumer will choose the alternative which received the highest preference. Since these prefer- 
ence structures relate to hypothetical shopping centres, the effects of retail change on individual choice behaviour and turnover levels of the shopping centres in the study area may be predicted by generating new alternatives; these reflect the changes and enable choice behaviour to be simulated by applying the derived preference structures and decision rules to the resulting choice sets.

More specifically, the approach involves the following steps (see Timmermans, 1984). First, some measurement model is specified. Next, the hypothetical choice alternatives are generated. This step involves identifying the attributes which are considered important in influencing the choice behaviour of interest, defining these attributes in terms of attribute levels, and then combining these into hypothetical choice alternatives according to some experimental design. The choice of design is largely dictated by the chosen measurement model because complex measurement models cannot be estimated on the basis of simple experimental designs. Subsequently, subjects are requested to express their overall evaluation or preference for the resulting set of choice alternatives. These preference measures are then decomposed into the so-called part-worth utilities associated with the various attribute levels, given the a priori specified measurement model. The validity of the decomposition may be assessed by calculating some goodness of fit measure. Having derived the preference structures, the next step involves specifying a decision rule which predicts an individual's choice behaviour given the position of the choice alternatives on his or her subjective preference scale. In general, different types of decision rules may be considered. The first rule states that an individual will invariably choose the alternative included in his choice set which received the highest preference score. The second rule is not deterministic and states that choice probabilities are systematically related to preferences.

The simulation works as follows. First, the shopping centres are described in terms of the attributes included in the preference experiment. Next, for each individual separately, a choice set is identified using some submodel. The consumer's preference score for each shopping centre is then calculated by applying his part-worth preference function to the description of the shopping centres in terms of attribute levels. Given these preference scores, actual behaviour is simulated by implementing the decision rule. These predicted individual choices are then aggregated to yield an estimate of aggregate retail turnover. Impacts are simulated by defining retail plans in terms of the attribute levels included in the conjoint measurement model. This results in adjusted attribute levels of the shopping centres involved and hence in changes in preferences and subsequent choice behaviour. This process is repeated iteratively for some fixed time horizon.

Recently, Louviere and Woodworth (1983) developed an alternative approach. Basically, their approach involves measuring choices directly rather than constructing choices from preference ratings. Essentially, this approach amounts to estimating random utility models from experimental design data, that is, choices among hypothetical alternatives. These choice designs differ from preference designs in that the hypothetical choice alternatives should now be placed into choice sets. This can be done in a number of ways (Louviere \& Timmermans, 1987). Because one now deals with choices per se rather than preferences, the estimated choice model can be used directly to simulate consumer choice behaviour.

\section{A DECISION SUPPORT SYSTEM FOR RETAIL PLANNING}

The application of choice models to problems of retail planning commonly involves research institutes or universities in collecting the data, estimating the model and running a fixed number of scenarios. Retail planning processes usually involve a number of representatives of various parties (local government, local retailers, national chains, Ministry of Economic Affairs, consumer groups, etc.). In practice, this planning group proposes a number of scenarios to be 
considered and the analyst then runs his model to assess the impacts of such scenarios. His findings are then used to support the decision-making process as an input to the discussions or negotiations or as a way of formulating additional scenarios. Due to this formalized nature of the planning process, it can often take several weeks before the next meeting is held. Perhaps more problematic though, is that many research contracts include limits on the number of runs executed, which will often frustrate the planning process in that additional analyses require additional funding. Moreover, to assess the impacts of plans of local retailers which emerge later, the model has to be used several times. Hence, a need was felt to develop user-friendly computer software that can be considered as a decision support system for retail planning.

We will now describe some computer software that has been developed by the authors. The software consists of three main modules. First, the information base includes software to manage the necessary information. Second, the modelbase contains software to model consumer choice behaviour. Finally, the third part contains software to summarize the results of different scenarios and evaluate those scenarios on a series of criteria or system performance indicators which will assist the planning team in the decision-making process. Each module runs quite separately and uses the output of previous modules as input.

\subsection{Module 1: Database}

The database module enables users to input and manage the required data. This module can be used to simulate policy measures by changing, deleting or introducing shopping centres in future time periods, or by changing the number of inhabitants per residential zone or even changing the number of residential zones. The required data contains the following information.

\section{The Supply Side}

This part of the information base includes data about the location, size and type of shops. To calculate normative turnover figures for each shopping centre, normative turnover-to-floor space levels, disaggregated to type of shop are required. In addition, characteristics of shopping centres like the amount of parking facilities, type of shopping centre, and so on, are required.

\section{The Transportation Network}

To calculate travel times between residential zones and shopping centres, a transportation network has to be specified, including any future alterations. Alternatively, a matrix of travel times might be specified.

\section{Population Figures and Expenditures}

To predict the turnover in each shopping centre in the future, the development of the number of inhabitants per residential zone and their expenditures need to be known. In addition, the outflow of expenditures to shopping centres in external zones and the inflow of expenditures of consumers living in external zones must be assessed.

\section{Choice Behaviour}

To estimate the parameters of the model, data is required concerning consumer choice behaviour. The required data depends on the type of model used. If a spatial interaction model is used, a so-called observed interaction matrix should be constructed. Each cell of this matrix contains the number of times a particular shopping centre is being visited by consumers living in a particular residential zone. In the case where a random utility model is used, much more information is required. First, for each respondent, the set of available shopping centres has to be identified. Second, the number of times a respondent visits each available shopping centre is 
required. Third, the attribute scores of the available shopping centres as perceived by the respondent are needed. In the case of the simulator system, depending on whether a preference task or a choice task is being applied, individual preferences or intended choices are required. To assess the applicability of the simulator system in practice, observed choice behaviour is required as well.

\subsection{Module 2: Modelbase}

This part of the decision support system contains software to calibrate a consumer choice model and to predict consumer choice behaviour using the calibrated model. For each type of model, a separate computer program is available. In addition, a program to determine the goodness-of-fit between observed (or intended) choice behaviour and choice behaviour predicted by the model is available.

\section{Spinmo}

The SPINMO (SPatial INtcraction MOdelling) program (Borgers \& Timmermans, 1988) uses the scores of the shopping centres on one or more attributes and a matrix of distances between residential zones and shopping centres to model the observed flows of consumers. Several distance functions can be specified, for example, a power function, an exponential function or a combination of both. SPINMO minimizes the sum of squared deviances between obscrved and predicted flows by means of a gradient search and/or a sequential search method.

\section{Caldis}

The CALDIS (CALibration of DIScrete choice models) program (Borgers, 1985) was developed to calibrate several types of discrete choice models. The PC-version of CALDIS, however, only contains the multinomial logit model. The program estimates the weights of the attributes given the number of times each individual chooses each available shopping centre and the attribute scores as perceived by the individuals. The program uses the log-likelihood as an optimization criterion. Like the SPINMO program, CALDIS uses a gradient and/or a sequential search method to find the optimal point in the parameter space. After predicting individual choice frequencies, both observed and predicted individual choice behaviour can be aggregated into flows between residential zones and shopping centres.

\section{Giant}

The GIANT (Generation, Implementation \& ANalysis of Treatments) system (Timmermans \& Borgers, 1989), part of which is still being developed, can be considered as an expert system to assist the analyst in constructing and analyzing conjoint-based simulator systems. The design of experiments, which is required in using such a modelling approach, demands some expert-knowledge which is often not available. This program aims at filling this gap. It should be emphasized that the system is thus not specifically developed for retail planning applications. It is a program to support the formulation of decompositional preference and choice models and analyze human decision making and choice behaviour in general. The program may thus be of use in all possible kinds of planning and policy-making contexts which relate to preferences and choice behaviour.

The program is menu-driven. It allows the user (a) to construct designs and generate experimental tasks, (b) to input and control subjects' responses to such experimental tasks, (c) to estimate preference functions and choice models from these experimental designs data, and (d) to simulate actual choice behaviour using the estimated preference functions or choice models.

The most difficult part in developing these models is the construction of experimental designs that allow estimating the required model. GIANT allows the user to address this prob- 
lem at four levels of sophistication and expertise. The inexperienced user can choose from a number of typical problems for which the modelling approach may be used. Depending upon the chosen option, the program then raises some additional questions and finally constructs the required designs. This option might also be used by an experienced user to deal with standard problems. At the next, more sophisticated level the system can be used to answer a series of questions and the system then determines whether a suitable experimental design can be constructed. A third option allows the user to use an experimental design from the data base of the program. Finally, the program contains an option to construct one's own design. Evidently, this option requires sufficient knowledge on the part of the user, but the system provides a number of analytic modules to assist the user in understanding the properties of the constructed design.

Several standard problems are incorporated in the system design. One such problem is that of conjoint preference measurement. This option should be chosen if one wishes to measure individual preferences for hypothetical choice alternatives. The program enables the user to construct the hypothetical choice alternatives so that individual overall preference measures can be decomposed into part-worth utilities for the attribute levels. Another standard problem concerns the estimation of the impacts of possible modifications in existing alternatives. In this case, the program generates a number of treatments. The proposed modifications and their levels are varied over the treatments so that the effect of each modification can be assessed. Still another problem concerns the prediction of market shares in so-called variable markets. Choice sets varying in size and composition are constructed to provide insight into expressed choice behaviour.

To deal with such problems, several decisions have to be made. In the most simple mode, decisions are made by the system which confronts the user only with those options that leave some freedom of choice. All decisions that are logically required to deal with a certain problem are made automatically. In the other modes, these decisions have to be made by the user. The system only warns against inconsistencies and improper solutions and provides some additional information.

The most important decision in this respect is whether the user wishes to implement a preference design or a choice design because this decision dictates many of the subsequent decisions, schemes of analyses and simulations. If a choice task is selected, the user has to decide whether to use a paired comparison design or a multiple comparison design. A paired comparison design has often some advantages, but a multiple comparison design should be chosen whenever one wishes to examine extended choice sets. The system has several options to construct such multiple comparison designs. In particular, it allows the construction of single fractional factorial designs, split plot designs, foldover designs, and randomized designs. If required, the statistical properties of the design are displayed and the user is guarded against making faults. The system also allows the user to include a base alternative to each choice set and to construct either fixed or varying choice set designs.

Having generated a design, the program can be used to output the experimental tasks. The user is requested to name the choice alternatives, attributes, and attribute levels assumed to affect consumer behaviour. In addition, the system permits inputting additional texts introducing the experimental task or specifying the measurement scale. A simple text-processing routine is written to help the user in describing the design and the experimental task. Important for many applied research projects is that the system allows the user to randomize the choice sets, choice alternatives, attributes and/or attribute levels across subjects. This is a very time-consuming task if the designs are constructed by hand and therefore this option is often omitted in practice at the risk of introducing different kinds of biases in the measurement.

The next main part of the computer program allows the user to input the responses to the constructed experimental tasks. Again, several options are available. Ranking, ratings, single choice and allocation data may be input, and whenever possible, the input data are automatical- 
ly checked. The system contains also a number of routines to convert data. Ratings may be converted into rankings; rankings may be exploited to generate choice data; allocation data can be converted into single choice data.

Once the response data are available the preference or choice model can be estimated. Several estimation procedures may be used, depending upon the scale properties and the kind of model one wishes to use (for details, see Timmermans, 1984). A necessary step in the estimation involves the construction of a design matrix. That is, the design has to be coded in terms of a series of indicator variables. GIANT allows a choice among four coding schemes: dummy coding, effect coding, orthogonal polynomials and a scheme suggested by Louviere (1988). Part of the coding depends upon the model specification and the problem studied. This part of the coding is handled automatically. The coded data can then be used in routines that analyze the data and estimate the specified model. To assist the user in interpreting the results of the analysis, the program generates a couple of summary statistics such as mean coefficients, graphical plots, analyses of monotonicity and tabulations of goodness-of-fit measures.

Finally, the system can be used to perform the simulation and assess the likely impacts of designated policy options or plans. The system allows the use of deterministic choice rules, various probabilistic choice rules, and several direct choice models. Information about market shares is provided.

\section{GOF}

Before using the specified model to predict the likely impacts of retail plans, the validity of the model has to be determined. This can be done by comparing predicted flows of consumers between residential zones and shopping centres with observed flows of consumers. The program GOF calculates several Goodness-Of-Fit measures (see Timmermans \& Borgers, 1985) between predicted and observed flows of consumers and between the predicted and observed number of consumers for each shopping centre.

\subsection{Module 3: Evaluation}

In practice, several alternative plans concerning the spatial retail system are usually considered. The planning team has to decide which plan is most desirable. Given the likely impacts of each plan on several criteria, the selection process can be supported by some multi-criteria evaluation system. The evaluation system uses a number of system performance indicators as criteria (van der Heijden, 1986). The indicators compare the impacts of a specific plan to the impacts of the so-called trend scenarios (when no policy measures are realized). Alternatively, the impacts of a specific plan may be compared to normative estimates. In addition to the indicators, user determined criteria can be used to evaluate these alternative retail plans.

The evaluation technique implemented belongs to the category of mixed data evaluation techniques (see Voogd, 1983). The advantage of mixed data multicriteria evaluation techniques is their ability to process both quantitative and qualitative criteria. Although the system performance indicators always imply quantitative criteria, the user may wish to add criteria of a qualitative nature. In addition to a matrix of scores of each retail plan on the criteria, a vector of weights has to be specified. These weights reflect the importance attached to the various criteria. In practice, the weights have to be specified by the planning team.

The system performance indicators can be distinguished in terms of three types. Indicators of retailers' interest refer to the economic functioning of the shopping centres. Indicators of consumer interest concern the availability of shopping facilities for consumers living in the residential zones. Finally, indicators of public interest concern items such as the equality of distribution with respect to the accessibility of consumers to shopping centres and the over and under allocation of expenditures to shopping centres. 


\section{Indicators of Retailers' Interest}

It is important for the planning team to get insight into the development of the turnover-tofloor space ratio given some plan as compared to the development according to the trend. The turnover-to-floor space (T-t-F) figures are considered as a surrogate measure of efficiency. The first indicator of retail interest is determined by calculating the ratio T-t-F(plan)/T-t-F(trend) for each shopping centre at each time period. A ratio less than 1.0 indicates a negative impact for the retailers in the specified shopping centre in the specified time period. By calculating the mean value over all shopping centres and all time periods, an average indicator for the plan under consideration results.

Another indicator of retailers interest is based upon the number of times the T-t-F(plan) is lower than the T-t-F(trend) for a particular shopping centre over all time periods. Averaging over all shopping centres and dividing this average value by the number of time periods gives a second indicator for the proposed plan.

\section{Indicators of Consumers' Interest}

For consumers, the available shopping opportunities are important. Therefore, indicators of consumers' interest are based on the available amount of floor space and number of shops for consumers living in a particular residential zone. To determine which shopping centres are available, some (residential zone specific) distance threshold has to be specified. The available shopping opportunities for consumers living in a specific residential zone according to the proposed plan can be compared to the available shopping opportunities according to the trend by calculating the ratio between both figures. An overall indicator can be determined by averaging the ratios over all residential zones and time periods. Such overall indicators can be calculated for the availability of floor space, floor space per branch, number of shops, number of shops per branch, number of different branches, and so on.

Changes in the local access of the shopping centres can be measured by summing the expenditures in the nearest shopping centre over the residential zones and time periods. Dividing this sum of expenditures by the sum of expenditures in the nearest shopping centres for the trend gives another indicator of consumer interests. Of course, this indicator can be disaggregated according to various branches of shopping types.

\section{Indicators of Public Interest}

In general, minimizing travel distances is considered as a planning objective. For a plan under consideration, the average distance travelled by consumers can be calculated. The first indicator of public interest equals the ratio of the average distance under the conditions of the proposed plan and the average distance for the trend. Another general planning objective concerns equality in the retail system. Policy measures should pursue equality between retailers and between consumers. Equality between retailers can be assessed by calculating some measure of deviation in the vector containing the averaged turnover-to-floor space ratio for each shopping centre. Equality between consumers can be determined by calculating a measure of deviation in the vector containing the averaged amount of available shopping facilities per residential zone.

\section{EPILOGUE}

In this paper, we have described a decision support and expert system for retail planning. The computer package, parts of which are still being developed, contains a database manager, a modelbase and an evaluation module. So far, the system is being used both in a scientific environment to get more insight into spatial choice behaviour, and in an applied planning context.

In two main cities of the Netherlands, the so-called PEARL system (Borgers \& Timmermans, 1987) is used to predict the effects of retail plans proposed by the local govern- 
ment or by local retailers. PEARL is an abridged version of the decision support system described above. The modelbase contains software to predict consumer choice behaviour at the aggregate level. The models were calibrated at our department using observed consumer choice behaviour. As yet, the evaluation module only relates predicted turnover-to-floor space figures to normative turnover-to-floor space figures.

To predict the effects of a new retail plan, the plan has to be converted into new attribute scores (floor space, price setting, distances, etc.) for the shopping centres under consideration. These data have to be entered by means of the data manager. After predicting consumer choice behaviour, the system produces and compares predicted turnover-to-floor space figures to normative figures. Otherwise, the system can be used to evaluate the effects of alternative residential building programs with respect to the economic functioning of the associated shopping centres.

\section{REFERENCES}

Ben-Akiva, M., \& Lerman, S. R. (1985). Discrete choice analysis: Theory and application to travel demand. Cambridge, MA: The MIT Press.

Borgers, A. (1985). CALDIS: A computer program for the calibration of discrete choice models. Urban Planning Group, University of Technology, Eindhoven, The Netherlands.

Borgers, A., \& Timmermans, H. (1987). PEARL: A computer program to predict the effects of alternative retail layouts (in Dutch). Urban Planning Group, University of Technology, Eindhoven, The Netherlands.

Borgers, A., \& Timmermans, H. (1988). SPINMO: A computer program for spatial interaction modelling. Urban Planning Group, University of Technology, Eindhoven, The Netherlands.

Golledge, R., \& Timmermans, H. (Eds.). (1988). Behavioural modelling in geography and planning. London: Croom Helm.

Louviere, J. (1988). Analyzing decision making: Metric conjoint analysis. Newbury Park, UK: Sage Publications.

Louviere, J., \& Timmermans, H. (1987). A review of some recent advances in decompositional preference and choice models. Paper presented at the 5th European Colloquium on Quantitative Theoretical Geography, Bardoneccia, Italy.

Louviere, J., \& Woodworth, G. (1983). Design and analysis of simulated consumer choice or allocation experiments: an approach based on aggregate data. Journal of Marketing Research, 20, 350-367.

McFadden, D. (1974). Conditional logit analysis of qualitative choice behaviour. In P. Zarembka (Ed.), Frontiers in econometrics (pp. 105-142). New York: Academic Press.

Roy, J., \& Anderson, M. (1988). Assessing impacts of retail development and redevelopment. In P. Newton, M. Taylor, \& R. Sharpe (Eds.), Desktop planning: Microcomputer applications for infrastructure and services planning and management (pp. 172-179). Melbourne, Australia: Hargreen Publishing Company.

Timmermans, H. (1984). Decompositional multiattribute preference models in spatial choice analysis. Progress in Human Geography, 8, 189-221.

Timmermans, H., \& Borgers, A. (1985). On the assessment of model performance in spatial choice analysis. In G. Bahrenberg \& J. Deiters (Eds.), Methodology, models and methods in regional science (pp. 33-63). Osnabrük, Germany: OSG.

Timmermans, H., \& Borgers, A. (1989). GIANT: A computer program for the generation, implementation and analysis of treatments. Urban Planning Group, University of Technology, Eindhoven, The Netherlands.

van der Heijden, R. (1986). A decision support system for the planning of retail facilities: Theory, methodology and application. PhD dissertation, Urban Planning Group, University of Technology, Eindhoven, The Netherlands.

van der Heijden, R., \& Timmermans, H. (1984). Modelling choice-set generating processes via stepwise logit regression procedures: Some empirical results. Environment and Planning A, 16, 1249-1255.

Voogd, H. (1983). Multicriteria evaluations for urban and regional planning. London: Pion.

Wilson, A. (1971). A family of spatial interaction models and associated developments. Environment and Planning A, 3, 1-32. 